\title{
Selection of Suitable Carbon, Nitrogen and Sulphate Source for the Production of Alkaline Protease by Bacillus licheniformis NCIM-2042
}

\author{
Biswanath BHUNIA, Debjani DUTTA, Surabhi CHAUDHURI \\ National Institute of Technology, Department of Biotechnology, Durgapur, Mahatma Gandhi Avenue, Durgapur-713209, \\ India; bbhunia@gmail.com (correspondingauthor)
}

\begin{abstract}
In this study, selection of suitable carbon, nitrogen and sulphate sources were carried out by one-variable-at-time approach for the production of alkaline protease enzyme by Bacillus licheniformis NCIM-2042. Maximum levels of alkaline protease were found in culture media supplemented with magnesium sulphate, starch and soybean meal as a good sulphate, carbon and nitrogen sources which influenced the maximum yield of this enzyme $(137.69 \pm 4.57,135.23 \pm 1.73$ and $134.74 \pm 1.77$, respectively) in comparison with the other sulphate, carbon and nitrogen sources.
\end{abstract}

Keywords: one-variable-at-time, alkaline protease, bacillus, culture medium, production

\section{Introduction}

A protease enzyme hydrolyses the peptide bonds that link amino acids together in the polypeptide chain forming a protein molecule. Proteases are essential constituents of all forms of life on earth, including prokaryotes, fungi, plants and animals. It can be cultured in large quantities in a relatively short time by established methods of fermentation and they also produce an abundant, regular supply of the desired product (Gupta et al., 2002). Alkaline proteases are defined as those proteases that are active in a neutral to alkaline $\mathrm{pH}$ range. They are either a serine protease or a metalloprotease.

Alkaline proteases enjoy a big share of the enzyme market with two thirds of share in detergent industry alone (Anwar and Saleemuddin, 2000). Besides they are also used in leather, food and textile industries; organic synthesis and waste water treatment (Kumar and Takagi, 1999). Microbial alkaline proteases occupy nearly $40 \%$ of the total worldwide enzyme sales and use of protease in detergent industry accounts $25 \%$ of the total worldwide sales of enzyme (Rao et al., 1998). A micro-organism is excellent source of enzyme, better than plants or animal due to their broad biochemical diversity, feasibility of mass culture and ease of genetic manipulation (Patel et al., 2005). Alkaline proteases can be produced from bacteria, fungi and yeast using fermentation technique (Chandran et al., 2005; Germano et al., 2003; Haki and Rakshit, 2003). Although there are several microbial alkaline proteases producers, only a few are considered industrially useful (Gupta $e t$ al., 2002). Gram-positive bacteria, especially the genus Bacillus are considered an important commercial enzyme pro- ducer of proteases. Of them, Bacillus lichniformis, Bacillus subtilis, Bacillus alcalophilus, Bacillus lentus, for instance, are industrial protease producers (Gupta et al., 2002).

Keeping in view of the demand, usefulness of the proteases in the industry, it is very important to focus on their overall production. Rapid enzyme production can be achieved by improvements in media composition and physical parameters (Moon and Parulekar, 1993; Oberoi et al., 2001). There is no universal medium for protease production for different microbial strains (Pandey et al., 2000) because each microorganism has its own individual physicochemical and nutritional requirements for growth and enzyme secretion. Accurate process optimization influences the activities of microorganisms and improves the production significantly, which is desirable for minimization of processing cost. In biotechnological enzyme production processes, even small improvements have been significant for commercial success (Reddy et al., 2008). Thus, development of a cost-effective medium for production of alkaline protease requires selection of carbon source, nitrogen source and inorganic salts at first and then nutritional requirement can be optimized by the statistical methods. However, the one-variable-at-time approach may be useful for important inhibitory or stimulation variables prior to conducting statistical methods.

In this study, selection of carbon, nitrogen and sulphate sources were carried out by the classical method involving one variable at a time approach for extracellular alkaline protease production from Bacillus licheniformis NCIM2042. It is known that carbon, nitrogen and sulphate sources are considered to contribute alkaline protease production from Bacillus sp. (Chauhan and Gupta, 2004). 


\section{Materials and methods}

Casein for protease assay was purchased from Himedia. All other medium chemical components used were of analytical grade, commercially available in India. All experiments have been done in triplicate.

Protease producing Bacillus licheniformis NCIM-2042 was procured from National Chemical Laboratory, Pune, India. The microorganism was grown on nutrient agar slants at $37^{\circ} \mathrm{C}$ at $\mathrm{pH} 7.4$. It was maintained by sub-culturing on nutrient agar slants kept at $\mathrm{pH}$ 7.4. For production experiments, the culture was revived by adding a loop full of pure culture into $50 \mathrm{ml}$ of sterile nutrient broth. For protease production, $50 \mathrm{ml}$ complex medium taken in 250 $\mathrm{ml}$ Erlenmeyer flask containing $\left(\mathrm{gl}^{-1}\right)$ : starch, 20; soybean meal, 10; $\mathrm{K}_{2} \mathrm{HPO}_{4}, 3 ; \mathrm{KH}_{2} \mathrm{PO}_{4}$, 1 ; at pH-7 (Oberoi et al., 2001 ) was inoculated with $2 \%$ fresh culture $\left(\mathrm{A}_{550 \mathrm{~nm}} \approx 0.2\right)$. The inoculated medium was incubated at $37^{\circ} \mathrm{C}$ and 180 $\mathrm{rpm}$. The culture was centrifuged at $10.000 \times g$ for $10 \mathrm{~min}$ at $4^{\circ} \mathrm{C}$. The cell pellet was discarded and the supernatant was used for assay of protease activity.

Protease activity was determined by a modified method of Folin and Ciocalteu (Folin and Ciocalteu, 1927). $200 \mu \mathrm{l}$ of the protease broth was added to the reaction mixture, containing $0.65 \%\left(\mathrm{wv}^{-1}\right)$ casein in $800 \mu \mathrm{l}$ of 50 $\mathrm{mM}$ in phosphate buffer ( $\mathrm{pH} 9)$. The mixture was incubated at $75^{\circ} \mathrm{C}$ for $10 \mathrm{~min}$. The reaction was stopped by the addition of $1 \mathrm{ml}$ of $5 \%\left(\mathrm{wv}^{-1}\right)$ trichloroacetic acid (TCA), followed by centrifugation at $10.000 \times g$ for $15 \mathrm{~min}$. The supernatant were analyzed by the Folin-Ciocalteu reagent. One unit of protease activity was defined as the amount of enzyme that liberated $1 \mu \mathrm{g}$ tyrosine per min per $\mathrm{ml}$ of protease broth.

Selection of carbon source was done by one variable at a time method where in the production medium, starch was replaced by different carbon sources viz. D-mannitol, glycerol, maltose, lactose, sucrose, glucose, mannose and fructose. All carbon sources were used at a final concentration of 1\% Carbon $\left(w^{-1}\right)$ (Puri et al., 2002a). Selection of nitrogen source was done by one variable at a time method where various organic and inorganic nitrogen sources were added to the fermentation medium at a final concentration of $0.5 \%$ Nitrogen $\left(\mathrm{wv}^{-1}\right)$ (Puri et al., 2002). To study the effect of different nitrogen sources on protease production, soybean meal was replaced by other organic as well as inorganic nitrogen sources such as peptone, casamino acid, gelatine, tryptone, urea, yeast extract, sodium nitrate, ammonium nitrate, ammonium chloride, ammonium sulphate and potassium nitrate. Selection of sulphate source was carried out by one variable at a time method where various metal sulphates sources such as magnesium sulphate, ferrous sulphate and calcium sulphate were added to the fermentation medium at a final concentration of $\mathrm{ggl}^{-1}$. Protease yield was determined after $96 \mathrm{~h}$ of incubation at $37^{\circ} \mathrm{C}$ and $180 \mathrm{rpm}$.
Simulated media was prepared by incorporating starch, soybean meal and magnesium sulphate as $1 \%$ Carbon $\left(\mathrm{wv}^{-1}\right), 0.5 \%$ Nitrogen $\left(\mathrm{wv}^{-1}\right)$ and $1 \mathrm{gl}^{-1}$ and protease production was compared with basal media after $96 \mathrm{~h}$ of incubation at $37^{\circ} \mathrm{C}$ and $180 \mathrm{rpm}$.

\section{Results and discussion}

Maximum alkaline protease production was realised when the medium comprised of starch, soybean meal and magnesium sulphate as carbon, nitrogen and sulphate sources respectively. Maximum extracellular alkaline protease production was obtained in presence of starch, as a complex carbon source, producing $135.23 \pm 1.72(\mathrm{U})$ which is the maximum yield in comparison with the other carbon sources (shown in Fig. 1). The protease production by other carbon sources were as follows: lactose (119.94 \pm 4.31$)$,

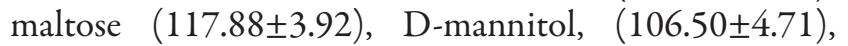
sucrose $(98.55 \pm 2.61)$, glycerol $(62.27 \pm 4.31)$, fructose (39.82 \pm 2.78$)$; mannose (38.54 \pm 3.07$)$ and glucose (32.36 \pm 3.39 ); which seemingly have less influence on protease production when compared to that of starch. These results were in accordance to previous reports for Bacillus sp. (Ferrero et al., 1996, Gusek et al., 1988, Hubner et al., 1993, Puri et al., 2002b). Repressive effect on protease synthesis was observed in this experiment when other carbon sources were used. Catabolite repression may be the most likely reason for this lagging effect (Kumar et al., 1999, Priest, 1977). It was previously established that a catabolite control protein $(\mathrm{CcpA})$ was responsible for this regulatory mechanisms which transduced signal for the repression in protease synthesis (Tobisch et al., 1999).

Maximum extracellular alkaline protease production was obtained in presence of soybean meal, as a complex nitrogen source, producing $134.74 \pm 1.77(\mathrm{U})$ which is the maximum yield in comparison with the other nitrogen sources (shown in Fig. 2). The protease production by other nitrogen sources are as follows: peptone $(131.90 \pm 4.18)$, gelatine $(89.34 \pm 2.67)$, sodium nitrate $(80.12 \pm 2.50)$, po-

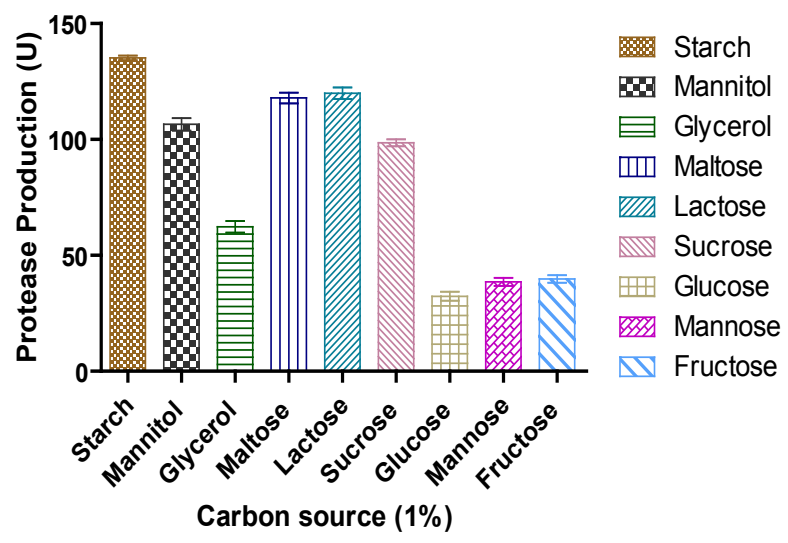

Fig. 1. Effect of different carbon sources on alkaline protease production 
58

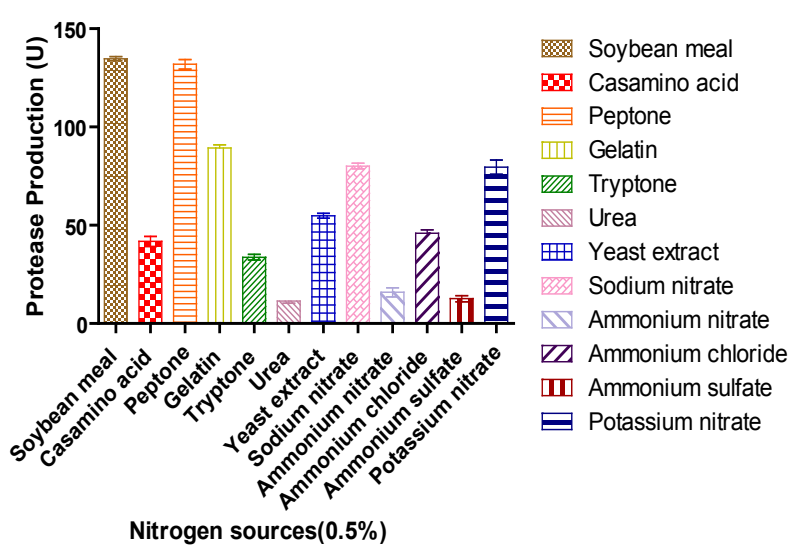

Fig. 2. Effect of different nitrogen sources on alkaline protease production

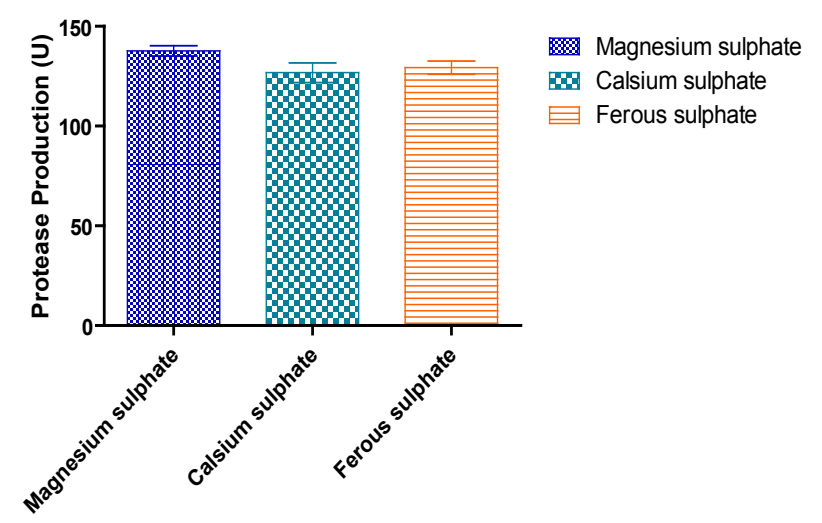

Fig. 3. Effect of different sulphate sources on alkaline protease production

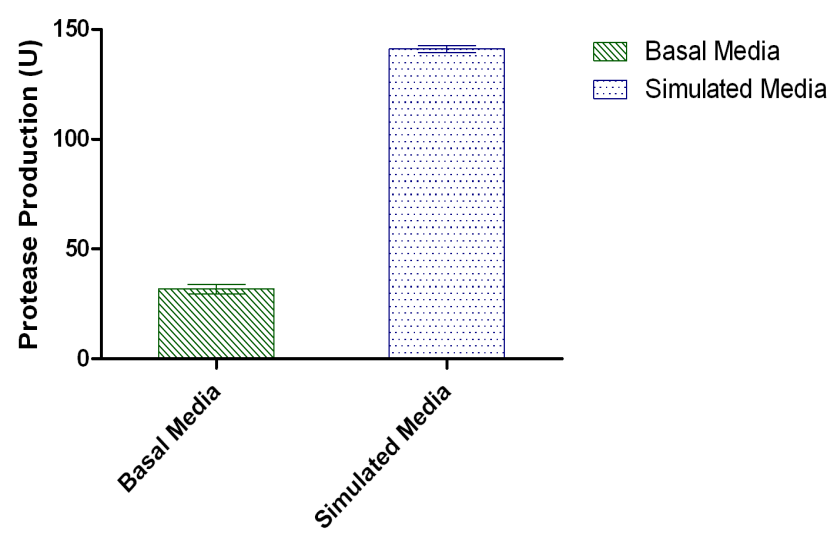

Fig. 4. Comparative study of protease production with Basal and Simulated Media

tassium nitrate $(79.53 \pm 6.33)$, yeast extract $(54.82 \pm 2.17)$, ammonium chloride $(45.90 \pm 3.18)$, casamino acid $(41.78 \pm 4.44)$, tryptone $(33.73 \pm 2.45)$, ammonium nitrate (15.89 \pm 3.98$)$, ammonium sulphate $(12.66 \pm 2.70)$ and urea $(11.38 \pm 1.77)$, which seemingly have less influence on protease production when compared to that of soybean meal. These results are in accordance to previous reports for Bacillus sp. (Ferrero et al., 1996; Gupta et al., 2002; Hubner et al., 1993; Joo et al., 2002; Puri et al., 2002) and this can be explained by the mechanism of feedback inhibition (Malathi and Chakraborty, 1991).

Magnesium sulphate, when used as the sulphate source, produced $137.69 \pm 4.57(\mathrm{U})$ of protease whereas ferrous sulphate produced $129.25 \pm 5.71 \mathrm{U}$ and calcium sulphate $126.80 \pm 8.53(\mathrm{U})$ of protease (Fig. 3). Magnesium ion was found to be more effective in protease production than other metal ions. The depletion in magnesium ion results in decreased rate of enzyme production that ultimately affects the mechanism of protease synthesis (Hanlon et al., 1982).

A significant improvement (4.42-fold) in the alkaline protease production (shown in Fig. 4) by Bacillus licheniformis NCIM-2042 was found in simulated media than basal media.

\section{Conclusions}

The present study focused on selection of suitable carbon, nitrogen and sulphate sources as a media component for maximal alkaline protease production through microbial fermentation. It was observed that such study was of utmost important for obtaining higher degree of alkaline protease production as well as reduction of operating cost of the process. Selection of the suitable carbon, nitrogen and sulphate sources were done through classical method involving one variable at a time which is user friendly. Further experiments on this protease towards optimization of media componants are currently under way.

\section{References}

Anwar, A. and M. Saleemuddin (2000). Alkaline protease from Spilosoma obliqua: potential applications in bioformulations. Biotechnol. Appl. Biochem. 31:85-89.

Sandhya, C., A. Sumantha, G. Szakacs and A. Pandey (2005). Comparative evaluation of neutral protease production by Aspergillus oryzae in submerged and solid-state fermentation. Process. Biochem. 40:2689-2694.

Chauhan, B. and R. Gupta (2004). Application of statistical experimental design for optimization of alkaline protease production from Bacillus sp. RGR-14. Process. Biochem. 39:2115-2122.

Ferrero, M. A., G. R. Carto, C. M. Abate, M. D. Baigori and F. Sineriz (1996). Thermostable alkaline proteases of Bacillus licheniformis MIR 29: isolation, production and characterization. Appl. Microbiol. Biotechnol. 45:327-332.

Folin, O. and V. Ciocalteu (1927). On tyrosine and tryptophane determinations in proteins. J. Biol. Chem. 73:627-650.

Germano, S., A. Pandey, C. A. Osaku, S. N. Rocha and C. R. Soccol (2003). Characterization and stability of proteases from Penicillium sp. produced by solid-state fermentation. 
Enzyme. Microbial. Technol. 32:246-251.

Gupta, R., Q. K. Beg and P. Lorenz (2002). Bacterial alkaline proteases: molecular approaches and industrial applications. Appl. Microbiol. Biotechnol. 59:15-32.

Gusek, T. W., D. B. Wilson and J. E. Kinselle (1988). Influences of carbon source on production of heat stable protease from Thermomonospora fuscaYX. Appl. Microbiol. Biotechnol. 28:80-84.

Haki, G. D. and S. K. Rakshit (2003). Developments in industrially important thermostable enzymes: a review. Bioresour. Technol. 89:17-34.

Hanlon, G. W., N. A. Hodges and A. D. Russell (1982). The influence of glucose, ammonium and magnesium availability on the production of protease and bacitracin by Bacillus licheniformis. J. Gen. Microbiol. 128:845-851.

Hubner, U., U. Block and K. Schugerl (1993). Production of alkaline serine protease subtilisin Carlsberg by Bacillus licheniformis on complex medium in a stirred tank reactor. Appl. Microbiol. Biotechnol. 40:182-188.

Joo, H. S., C. G. Kumar, G. C. Park, K. M. Kim, S. R. Paik, and C. S. Chang (2002). Optimization of the production of an extracellular alkaline protease from Bacillus horikoshi. Process. Biochem. 38:155-159.

Kumar, C. G., R. K. Malik, M. P. Tiwari and K. D. Jany (1999). Optimal production of Bacillus alkaline protease using a cheese whey medium. Microbiologie des Alimentes et Nutrition. 17:39-48.

Kumar, C. G. and H. Takagi (1999). Microbial alkaline proteases: from a bioindustrial viewpoint. Biotechnol. Adv. 17:561-594.

Malathi, S. and R. Chakraborty (1991). Production of Alkaline Protease by a New Aspergillus flavus Isolate under SolidSubstrate Fermentation Conditions for Use as a Depilation Agent. Appl. Environ. Microbiol. 57:712-716.
Moon, S. H. and S. J. Parulekar (1993). Some observations on protease production in continuous suspension cultures of Bacillus firmus. Biotechnol. Bioeng. 41:43-54.

Oberoi, R., Q. K. Beg, S. Puri, R. K. Sexena and R. Gupta (2001). Characterization and wash performance analysis of an SDS-stable alkaline protease from a Bacillus sp. World. J. Microbiol. Biotechnol. 17:493-497.

Pandey, A., P. Nigam, C. R. Soccol, V. T. Soccol, D. Singh, and R. Mohan (2000). Advances in microbial amylases. Biotechnol. Appl. Biochem. 31(2):135-152.

Patel, R., M. Dodia and S. P. Singh (2005). Extracellular alkaline protease from a newly isolated haloalkaliphilic Bacillus sp.: Production and optimization. Process. Biochem. 40:35693575.

Priest, F. G. (1977). Extracellular enzyme synthesis in the genus Bacillus. Bacteriol. Rev. 41:711-753.

Puri, S., Q. K. Beg and R. Gupta (2002). Optimization of alkaline protease production from Bacillus $s p$. by response surface methodology. Curr. Microbiol. 44:286-290.

Rao, M. B., A. M. Tanksale, M. S. Ghatke and V. V. Deshpande (1998). Molecular biology and biotechnological aspects of microbial proteases. Microbiol. Molec. Biol. Rev. 62:597535.

Reddy, L. V., Y. J. Wee, J. S. Yun and H. W. Ryu (2008). Optimization of alkaline protease production by batch culture of Bacillus sp. RKY3 through Plackett-Burman and response surface methodological approaches. Bioresour. Technol. 99:2242-2249.

Tobisch, S., D. Zuhlke, J. Bernhardt, J. Stulke and M. Hecker (1999). Role of CcpA in regulation of the central pathways of carbon catabolism in Bacillus subtilis. J. Bacteriol. 181:6996-7004. 